Article Citation Format

Yerokun, O.M. \& Onyesolu, M.O. (2021):

On the Development of Neuro-Fuzzy Expert System for Detection of Leghemoglobin (NFESDL) in Legumes. Journal of Digital Innovations \& Contemp Res. In Science., Engineering \& Technology. Vol. 9, No. 1. Pp 129-140 DOI: dx.doi.org/10.22624/AIMS/DIGITAL/N9N1P1
Article Progress Time Stamps

Article Type: Research Article

Manuscript Received: $14^{\text {th }}$ Dec, 2020

Review Type: Blind

Final Acceptance:: 16 $6^{\text {th }}$ January, 2021

\title{
On the Development of Neuro-Fuzzy Expert System for Detection of Leghemoglobin (NFESDL) in Legumes
}

\author{
Yerokun, O.M.1 \& Onyesolu, M.0.2 \\ 1 Department of Computer Education, Federal College of Education (Technical), Asaba, Delta State. \\ 2Department of Computer Science, Nnamdi Azikiwe University, Awka, Anambra State.
}

E-mails: yerokunoluwatoyin@gmail.com; mo.onyesolu@unizik.edu.ng

\begin{abstract}
The regular supply of affordable complete meals most especially protein from animals has been threatened. Protein sourced from animals carry too many health risks. Obesity, cancer, diabetes, etc., have been traced to the consumption of meats, most especially beef. Medical experts claim that some ailments are as a result of the chemically processed feeds given to raise animals. Therefore, an alternative to meat from plants is imperative. This led to the development of a neuro-fuzzy expert system for detection of leghemoglobin in legumes. This work utilized production rule-base technique and forward-chaining mechanisms with linguistic antecedent conditions to detect the presence of leghemoglobin in plants. To further remove clumsiness and ambiguity in the identification process, metrics/weights were obtained and attached to each morphological feature. MATLAB platform was employed for the development of the system. Class and objects were used to model the information elicited. The result is a system that detects the presence of leghemoglobin in plants.
\end{abstract}

Keywords: Expert system, inference system, neuro-fuzzy, dataset, leghemoglobin

\section{INTRODUCTION}

Artificial Intelligence (Al) is the branch of computer science concerned with the automation of intelligent behavior (Vandal, 2010). A system is termed intelligent if it exhibits intelligent behavior. Al gave birth to intelligent systems. Intelligent behaviour is capable of achieving specified goals or sustaining desired behavior under conditions of uncertainty even in a poorly structured environment. Such environments include where various characteristics are not measurable or where several characteristics change simultaneously and in an unexpected way and where it is not possible to decide in advance how the system will respond to every combination of events (Olanloye, 2017). Intelligent behaviour of a computer is the ability to achieve the human-level performance in cognitive tasks (Negnevitsky, 2005). Intelligence means the capacity to learn, to acquire, adapt, modify and extend knowledge in order to solve problems. Thus, when building intelligent entities, problems cannot only be solved by human experts but also by artificial intelligence. 
One very successful application of $\mathrm{Al}$ technology is expert systems. McCarthy, who coined $\mathrm{Al}$, defined it as the science and engineering of making intelligent machines (MCcarthy, 2007). Al is the science and technology that is concerned with the development of computer systems that are capable of acting as human beings (Tung and Jintae, 1999). Al has produced machines that are capable of thinking, feeling, talking, hearing, touching, perceiving and seeing. Meaning that, any machine that can mimic the various cognitive functions attributed to only human beings is an intelligent machine. Since the evolution of the personal computer and the birth of integrated circuits, computer has found its way into every human endeavour, including the basic life line of food-from planting to harvesting, selection to balance of food nutrients, processing and production to distribution of food, up to and including diet scheduling, have all found computer science useful.

In 1976, the International Labour Organization (ILO) declared in a worldwide publication by United Nations (2017), that food, clothing, housing, education and public transportation are the five (5) basic needs of man. Food is thus the first and topmost priority of man, not just any food, but a balanced diet. Krans (2016) emphasized the declaration of ILO by asserting that a diet is balanced when it gives the body the nutrients it needs to function correctly. A diet is balanced when it consists of a variety of different types of food and provides adequate amounts of nutrients necessary for good health, provision of energy, body building, and regulation of body processes and protection against diseases.

Proteins, vitamin, carbohydrates, fats and oils, mineral salts and water are the six (6) classes of food. Protein is accorded $20 \%$ to $30 \%$ of daily food requirements (Collins, 2017) thus making protein a very significant part of daily needs in compliance with the ILO order on food. It is therefore important that protein in all its forms should be available, affordable and reachable by all. Nutrition experts such as Krans (2016) and Collins (2017) agree that meat is a very rich source of protein and meat from animals is one major source of protein. Protein is made up of smaller units known as amino acids. Amino acids, often referred to as the building blocks of proteins, are compounds that play many critical roles in the body. They are needed for vital processes like the building of proteins and synthesis of hormones and neurotransmitters (Kubala, 2018). Basically, protein is broadly divided into two: animal and plant based protein (Ware, 2017). Animal proteins are those protein obtained from animals such as, beef, milk, cheese, yoghurt, pork tenderloin, chicken, eggs and fish. Plant protein is obtained from plants (vegetable) such as nuts, legumes-beans (asparagus, green, kidney, navy, soy, pinto, garbanzo, adzuki, anasazi, wax, mung, dwarf), southern peas, English peas, snow peas, sugar snap peas, alfalfa, clover, lespedeza, lentils, licorice and peanuts (Allender, 2011).

Leguminous crops are plants in the family, Fabacea (formerly known as Leguminosae). They are grown primarily for their grain seed, livestock forage and their soil enhancing properties (Towler, 2014). This is as a result of the nitrogen-fixing nodules in their roots. Some legumes are eaten while some are used as fallow crops (tephrosia and mucuna). Some are shrubs (tephrosia) while some are small plants not more than ten centimeters in height (peanut). The two major groups of legumes are those that produce mainly fat and oil such as groundnuts and soya bean, and those that mainly produce protein such as cowpeas and beans (Yingling, 2017). Leghemoglobin is a compound found in leguminous plants. It is found in the nitrogen-fixing root nodules of leguminous plants. It is produced by legumes in response to the roots being colonized by nitrogen-fixing bacteria known as rhizobia, as part of the symbiotic interaction between plant and bacterium. Many roots which are not colonized by rhizobium cannot synthesize leghemoglobin. Leghemoglobin has close chemical and structural similarities to hemoglobin. Appropriately processed, leghemoglobin can meet the high demand for meat. Simply put, it is meat from plants, having the same nutritional value, content, taste, feel and look (Fraser et al., 2018). However, not all legumes have this substance in them. 
Food is a priority need of man (Nutrition and Dietetics, 2015), not just food but balanced and regular diet. There is a major threat to regular supply of affordable complete meals faced by all. Protein sourced from animals carry too many health risks. Various ailments (obesity, cancer, diabetes, etc.) have been traced to the consumption of meats, most especially beef. Similarly, medical experts claim that some ailments are as a result of the chemically processed feeds given to raise poultry birds (Krans, 2016). Generally, protein from animal source is considered as complete and therefore is mostly preferred to plant protein due to its unique taste derived from blood in animals and the fact that it contains all the essential amino acids, whereas, protein from plants is limited in one or more essential amino acids. For example, grains are limited in lysine and legumes are limited in methionine, two of the nine essential amino acids.

In Nigeria, the crises between herdsmen and the natives of various states for pastures as grazing of lands, has continued to escalate, therefore, the cost of raising animals primarily for food has become so high that an average family can barely afford meat to balance their dietary requirements. Meats also harbor so many disease-causing microorganisms, so much that basic healthy living diets exclude meats in their plans. This paper therefore seeks develop a neuro fuzzy expert system for the detection of leghemoglobin in plants based on their morphological features.

\section{RELATED WORKS}

Iraji and Tosinia (2011) developed an adaptive neuro-fuzzy inference system (ANFIS)-Sugeno, a neuro-fuzzy inference system for sorting and classification of tomatoes into appropriate market grades. ANFIS-Sugeno is a system that could make accurate decision based on the imported images to sort tomatoes into four categories-export quality, national quality, regional quality and salsa quality. The system asks questions and expected the end user to supply answers as input by selecting one or more from options provided by the system or by entering another set of data as input. Such interaction is continued until the system reaches a conclusion. Suhartono, Aditya, Lestari and Yasin (2013) designed and developed an expert system that detects coffee plant diseases at Bina Nusantara University, Jakarta, Indonesia. The focus of this work was to create a system that can help researchers or observers working in coffee plantation to diagnose coffee plants diseases. Decision trees of hierarchical classification were used to achieve the fuzzy logic based system. The designers built the knowledge base to the highest degree of trust and validity with IF-THEN rules by applying forward chaining technique.

Zhang (2015) developed an adaptive decoupling control and energy efficient system for meat drying processing. This work was based on neuro-fuzzy approaches to control relative humidity and temperature for the meat drying room. A functional coupling model was designed based on fuzzy logic and neuro-fuzzy method to decouple the influence of temperature and relative humidity due to the coupling impact in real-time drying room control process. The method effectively limited the coupling of temperature and relative humidity since the issue is caused by the internal drying room system or the external conditions. It reduced energy consumption with results based on real time measurements. Subsequently, the cost of food production and preservation was reduced with increase in quality and efficiency of production.

Shamkuwar, Thakre, More, Gajakosh, and Yewale (2018) developed an expert system for diagnosing plant disease using neural network. This work bears close relation to the work of Zhang (2015), except that Shamkuwar et al. (2018) used an image processing method that is able to create a smart phone application for the detection of plants diseases. It also used data mining concepts for the prediction of the disease and creating training datasets. Basically, it, used android applications with the good camera and sufficient RAM memory to capture the image of the plant leaf, extracted basic features from the image (required preprocessing to remove noisy data from leaf image), converts image to grayscale, identify the pattern of points, use segmentation algorithm to find out edges of the leaf, and apply Support Vector Machine (SVM) algorithm to formulate a forecasting of plant disease. 
The expert system's graphical user interface was designed using java JSP while the overall development was done with Eclipse 3.3 Indigo and SQL for its database.

Sitanggang et al. (2018) developed an application which used forward-chaining method in diagnosis of onion plant diseases. The knowledge base was first created with the forward-chaining up to input-output design, then by using rule-based reasoning method with IF, IF THEN pattern on the knowledge base, the experts with their performance solves various problems sequentially. The shell of expert system for text animation (ESTA) was used for the development of this system, mainly to produce a system that integrates a structured knowledge base along with solutions to the problems. The operations begin with the entry of symptoms by the user, after which the system goes through the process of reading data characteristics from the database then displays some matches for the user. The system waits for the user's response to the features displayed on the screen. If there is a match with certain characteristics of any onion diseases, more questions are asked the user based on the matches found, until a discrete conclusion is obtained and displayed. Sixteen (16) symptoms were used to train datasets that produced nine (9) diseases as conclusions or results. The results were added to the database for learning and further expansion of the knowledge base.

Wijaya, Hariono, Saputra, and Rukmi (2019) used back propagation technique in Artificial Neural Network (ANN) to develop a system based on image processing techniques to monitor growth of red spinach plants. A plant growth monitoring program was created with Borland Delphi 7 software and DS Pack version 2.3.4 component and ran the analysis/prediction on MATLAB. The system was aimed at reducing the complexity of image extraction from plants and simultaneously increasing the accuracy of results obtained from growth monitoring exercises. Multiple cameras were installed around the plants in what was referred to as photo-box, with lightings to ensure clear image capture every two days. Images were taken for thirty nine days from 236 plants. It combined image capture, coding and storing with its GUI capabilities to develop the model. The 236 images obtained were reduced to three input parameters to compile the dataset used for training and testing. Activation functions were based on the values of images from top, front and side, three inputs, four layers and one output. The value of $R^{2}$ and RMSE confirmed $98 \%$ accuracy prediction of fresh plant weights.

\section{MATERIALS AND METHODS}

This work utilized production rule-base technique and forward-chaining mechanisms with linguistic antecedent conditions to detect the presence of leghemoglobin in plants. To further remove clumsiness and ambiguity in the identification process, metrics/weights were obtained and attached to each morphological feature for precision which generated the dataset in Table 1; from this dataset in Table 1, the architecture in Figure 1 was developed. MATLAB platform was employed for the development of the system. Class and objects were used to model the information elicited. A class named Rule was created and houses various objects such as: Rule(), AddAntecedent(), setConsequent(), AddRule(), and AddFact() which serves as subsidiary methods. In order to model the identification of legume, rhizobia, leghaemoglobin processing a rule instance is created for each identification and a rule name is created and antencedents are added to the rule created using the Addantecedent() object to ascertain the conditions to be met to lead to the setconsequent (conclusion). This setconsequent (conclusion) was added using setConsequent() object for each identification. To query the inference engine the Addfact() object was used to provide facts entered into the system by users to the inference engine for antecedent cross-matching. 
Table 1: Input variables, ranges, and fuzzy sets

\begin{tabular}{lll}
\hline Input Variables & Ranges & Fuzzy Set \\
\hline & $<128$ & Dull \\
Color of Flower & $110-180$ & Bright \\
& $170-255$ & Very Bright \\
& $<0.30 \mathrm{~cm}$ & Very Small \\
Stipules & $0.25-0.60 \mathrm{~cm}$ & Small \\
& $0.50-1.00 \mathrm{~cm}$ & Large \\
& $<0.030 \mathrm{~mm}$ & Very Small \\
Pods & $0.025-0.060 \mathrm{~mm}$ & Small \\
& $0.050-0.100 \mathrm{~mm}$ & Large \\
Nodules & $<0.30 \mathrm{~cm}$ & Very Small \\
& $0.25-0.60 \mathrm{~cm}$ & Small \\
Color of Cross Section of Root & $0.50-1.00 \mathrm{~cm}$ & Large \\
(CCSR) & $<128$ & Dull \\
& $110-180$ & Bright \\
\end{tabular}

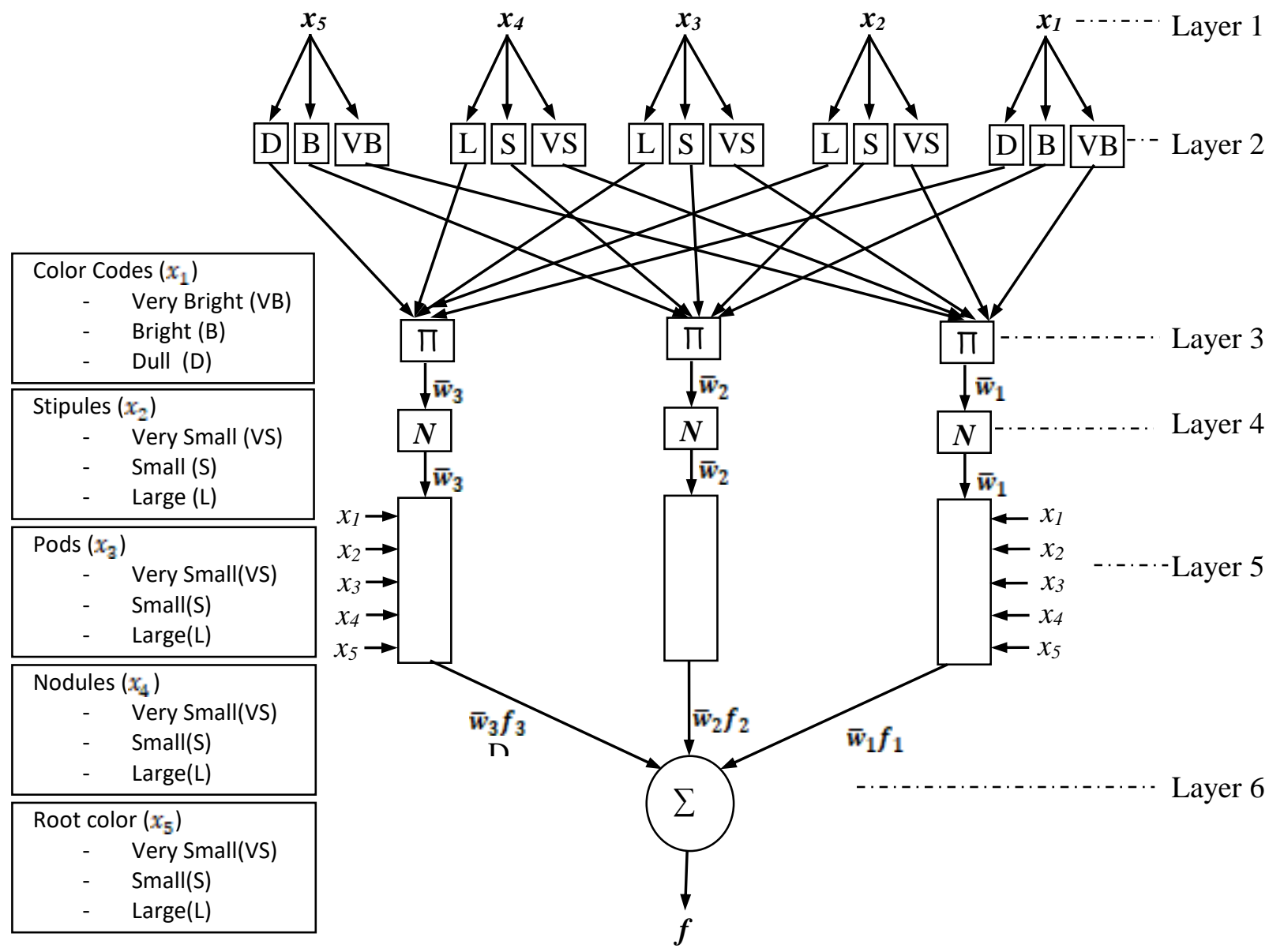

Figure 1: Architecture of the neuro-fuzzy inference system (Source: Authors) 


\subsection{The Architecture of the Neuro-Fuzzy Inference System for Detection of Leghemoglobin}

Layer 1 - This layer is referred to as the input layer. It consists of active nodes which denote inputs to the system. These inputs are crisp values that represent plant features such as the color of leaf, stipules, pods, nodules, and the color of roots. The output of this layer is linguistic terms corresponding to each of the input values.

Layer 2 - The fuzzification layer receives as input, the output from layer 1 (the input layer) and thereafter produces their corresponding membership function values using Equation (1).

$f_{2}=\mu_{A_{i}}(x)$

where $x$ is the input to the $i^{i \text { th }}$ node, $A_{\tilde{i}}$ represents the linguistic label characterized by membership $\mu$, and $f_{2}$ is the fuzzification value of fuzzy-set $A_{i}$ which can be trapezoidal, gaussian, and more This work separately used Triangular membership, Equation (2), Trapezoidal, Equation (8), Gaussian, Equation (9) , and combination of two Gaussian membership functions, Equation (10), for fuzzification of the different ANFIS model.

$$
\text { a. } \mu_{(X)}=\left\{\begin{array}{l}
\text { Triangular Membership function } \\
\frac{x-a}{b-a} \text { if } a \leq x \leq b \\
\frac{b-x}{a-b} \text { if } b \leq x \leq c \\
0 \quad \text { if } x>c
\end{array}\right.
$$

Where $a$ is the start point, $b$ represents the peak point, and end point of the linguistic term of the linguistic variable $x$ of input parameters (color of flower, stipule, pods, nodules, and the color of roots) respectively. However, the color of flower and color of roots use dull, bright, and very bright as fuzzy sets, while stipules, pods, and nodules use very small, small, and large fuzzy sets. Table 1 shows the input variables, ranges, and fuzzy sets as defined in Equation (3) to Equation (7).

$\mu_{\text {coloreode }}=\left\{\begin{array}{cc}0 & \text { if } x<128 \\ \frac{x-128}{180-128} & \text { if } 128 \leq x \leq 180 \\ \frac{180-x}{255-180} & \text { if } 180 \leq x \leq 255 \\ 0 & \text { if } x>255\end{array}\right.$

$$
\mu_{\text {stipulate }}=\left\{\begin{array}{cc}
0 & \text { if } x<0.3 \\
\frac{x-0.3}{0.6-0.3} & \text { if } 0.2 \leq x \leq 0.6 \\
\frac{0.6-x}{1.0-0.6} & \text { if } 0.6 \leq x \leq 1.0 \\
0 & \text { if } x>1.0
\end{array}\right.
$$




$$
\begin{gathered}
\mu_{\text {pods }}=\left\{\begin{array}{cc}
0 & \text { if } x<0.03 \\
\frac{x-0.03}{0.06-0.03} & \text { if } 0.03 \leq x \leq 0.06 \\
\frac{0.06-x}{0.1-0.06} & \text { if } 0.06 \leq x \leq 0.1 \\
0 & \text { if } x>0.1
\end{array}\right. \\
\mu_{\text {Nodules }}=\left\{\begin{array}{cc}
\frac{x-0.3}{0.6-0.3} & \text { if } 0.2 \leq x \leq 0.6 \\
\frac{0.6-x}{1.0-0.6} & \text { if } 0.6 \leq x \leq 1.0 \\
0 & \text { if } x>1.0
\end{array}\right. \\
\mu_{\text {CCSR }}=\left\{\begin{array}{cc}
\frac{1}{0} x & \text { if } x<128 \\
\frac{x-128}{180-128} & \text { if } 128 \leq x \leq 180 \\
\frac{180-x}{255-180} & \text { if } 180 \leq x \leq 255 \\
0 & \text { if } x>255
\end{array}\right.
\end{gathered}
$$

\section{c. Gaussian Membership}

$$
f_{2}=\mu_{A_{i}}(x)=e^{-\frac{\left[x-c_{i}\right)^{2}}{2 \sigma_{i}}}
$$

The variables $\left(c_{i}, \sigma_{i}\right)$ are the parameters of the membership function governing the Gaussian function. $c_{i}$, is the parameter for locating center and $\sigma_{\bar{i}}$ is the parameter for determining the width of the curve.

\section{d. Gaussian Combination Membership function (gauss2mf)}

Gauss $2 \mathrm{mf}$ is a combination of two parameters namely sig $g_{1}$ and $c_{1}$ as presented in Equation (10)

$y=\operatorname{gauss} 2 m f\left(x_{,}\left[\operatorname{sig}_{1} c_{1} \operatorname{sig}_{2} c_{2}\right]\right)$

The first function specified by $\operatorname{sig}_{1} c_{1}$ determines the shape of the left-most curve, the second function specified by $\operatorname{sig}_{2} c_{2}$ determines the shape of the right-most curve. Hence when $c_{1}<c_{2}$, gauss $2 \mathrm{mf}$ function reaches a maximum value of 1 . Otherwise, the maximum value is less than one. The Gaussian function has been used for specifying the fuzzy sets due to their smoothness and concise notation property and having the advantage of being smooth and nonzero at all points. 
Layer 3 - The third layer is also known as the AND operation layer. The layer is labeled $\Pi$ as it acts as multipliers. In this layer, each node calculates the firing strength of a rule. The output of this layer is presented as Equation (11):

$f_{3}=w_{i}=\mu_{A_{i}}\left(x_{1}\right) * \mu_{B_{i}}\left(x_{2}\right) * \mu_{C_{i}}\left(x_{3}\right) * \ldots ; * \mu_{M_{i}}\left(x_{n}\right)$

where $w_{i}$ is the firing strength of a rule and $A_{i}, B_{i}, C_{i}, \ldots, M_{i}$ are used to represent our linguistic labels.

Layer 4 - The fourth layer of the proposed ANFIS is the normalization layer labeled $\boldsymbol{N}$ in Figure 1. This layer plays a normalization role to the firing strengths (i.e., the degrees to which the antecedent part of a fuzzy rule is satisfied) from the previous layer. This is done by calculating the ratios of firing strength for rule ito the sum of all the rules firing strength. The output of this layer can be represented as Equation (12):

$f_{4}=\bar{w}=\frac{w_{i}^{i}}{\sum_{i=1}^{g} w}$

where $\bar{w}$ is the normalized weight

Layer 5 - This is the consequent nodes: The node function of the fifth layer computes the contribution of each $i^{\text {th }}$ rule towards the total output and the function defined as Equation (13):

$\mathrm{f}_{5}=\bar{w}_{i} f_{i}=\bar{w}_{i}\left(m_{i} x_{1}+n_{i} x_{2}+p_{i} x_{3}+r_{i} x_{4}+s_{i} x_{5}+t_{i}\right)$

where $\bar{w}_{i}$ is the $i^{\text {th }}$ node's output from the previous layer, $f_{i}$ represents ANFIS consequent parameters of learning rate while $\left\{m_{i}, n_{i}, p_{i}, r_{i}, t_{i}\right\}$ is the consequent parameter set.

Layer 6 - The last layer is ANFIS's final output also known as the defuzzification layer. This is a single fixed layer with label $F$ as shown in Figure 1. The layer is computed by summing all the incoming signals from the previous layer. Accordingly, the defuzzification process transforms each fuzzy rule result into a crisp output which is the identification result of whether a plant is a legume or not a legume. This is computed using Equation (14)

$f_{6}=\sum_{i=1}^{3} \bar{w}_{i} f_{i}=\frac{\sum_{i=1}^{3} w_{i} f_{i}}{\sum_{i=1}^{3} w_{i}}$

The Output-The output component displays the results obtained from the inference engine in a readable format to the user. The output also displays the evaluation result of what the model has predicted. These results are displayed via an interface which enables interaction between the user and the proposed system.

\section{RESULTS AND DISCUSSION}

The results of the system are shown in Figure 2 to Figure 8 . Figure 2 to Figure 8 show the screenshots of the system. Figure 2 is the control centre of the system. Figure 3 is the imported input data window. Imported target (output) data window is shown in Figure 4. Figure 5 presents the trained ANFIS model structure of the system. Figure 6 shows the ANFIS model structure (by direct workspace input). Figure 7 is the result windows showing presence or not of leghemoglobin. These aggregations made up the neuro-fuzzy expert system for detection of leghemoglobin in legumes (NFESDLL). 


\section{The Control Centre}

The control centre (Figure 2) is also referred to as the main user interface. This clearly displays the six submenu buttons namely import input data, import target data, membership function, train ANFIS model, clear data, test ANFIS model and detect. These submenu buttons give rise to other functions of the system.

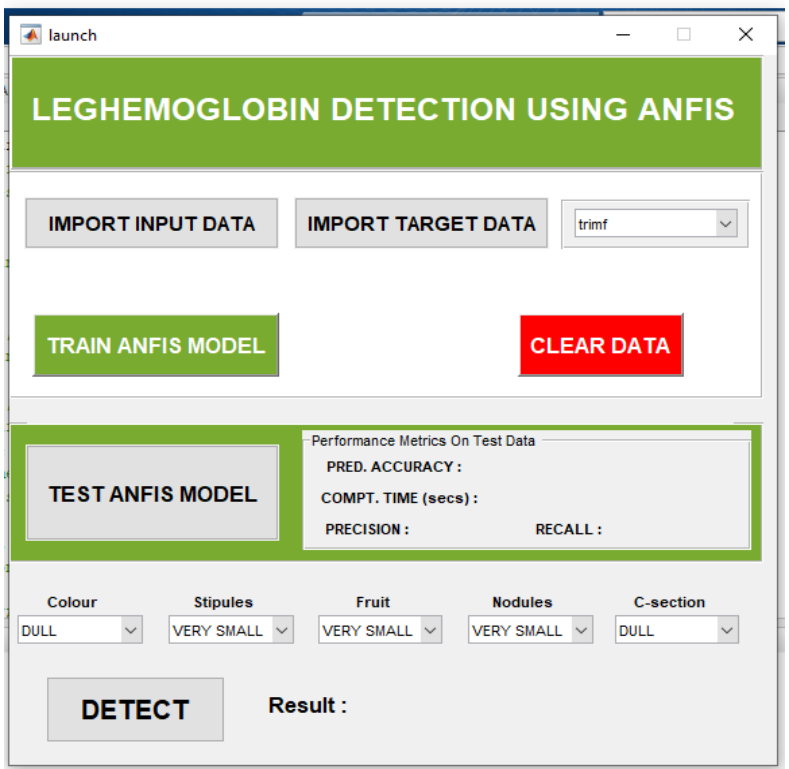

Figure 2: Control centre of the system

\section{Import Input Data}

The first step in the detection of leghemoglobin using this system is to import training dataset (using Figure 3). The training dataset is a collection of different plants including leguminuous plants described by their morphological features. Target data is the expected output result from the training.

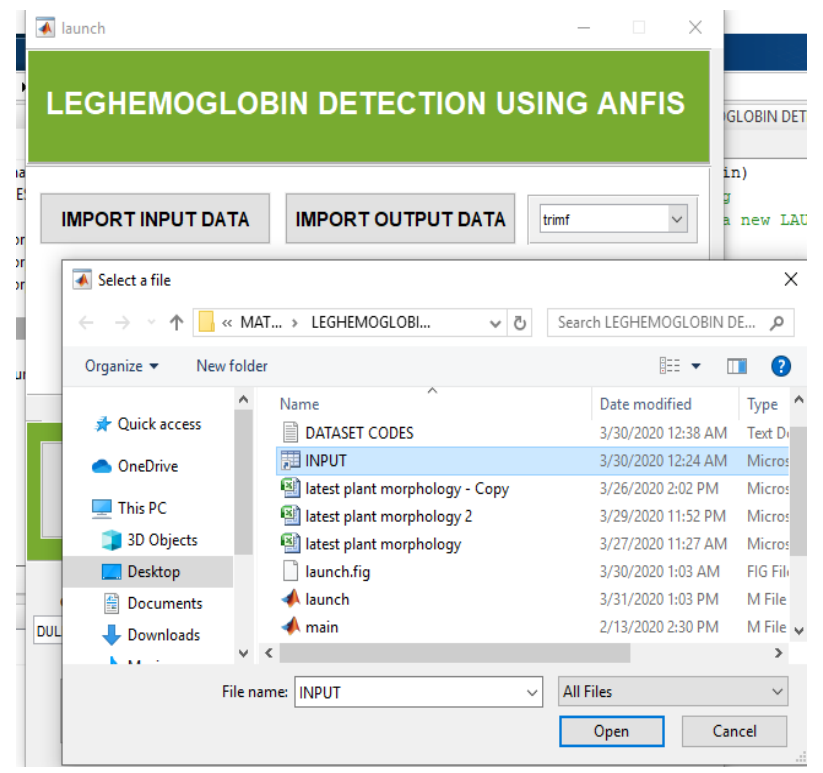

Figure 3: Imported input data window 


\section{Import Target Data}

The target data is the expected output data or result from training the ANFIS. It contains the class labels corresponding to each instance in the input data. The target data is required to train the ANFIS to learn the morphological features of the plants and to identify them correctly.

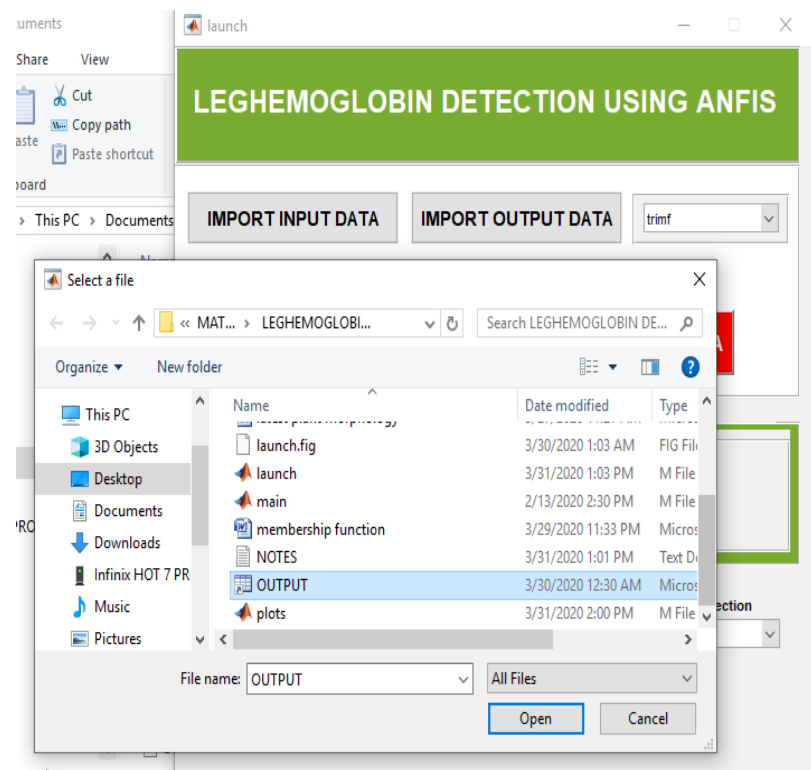

Figure 4: Imported target (output) data window

Figure 5 is the ANFIS structure obtained after successfully training the system with import data and target data.

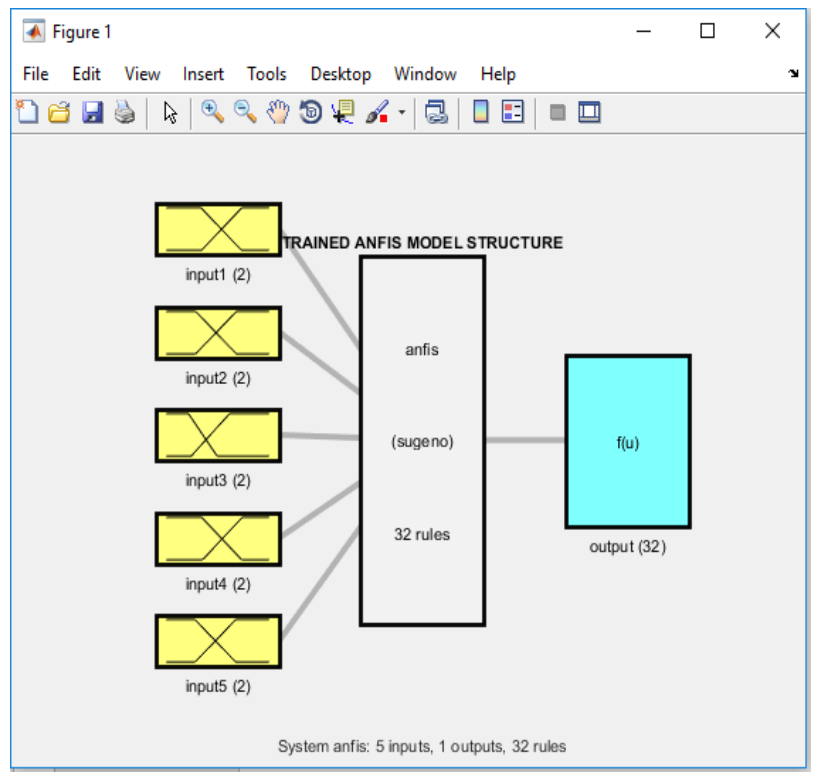

Figure 5: Trained ANFIS model structure of the system

Figure 6 is the model structure showing the layers, rules and operational interconnections of the system. 


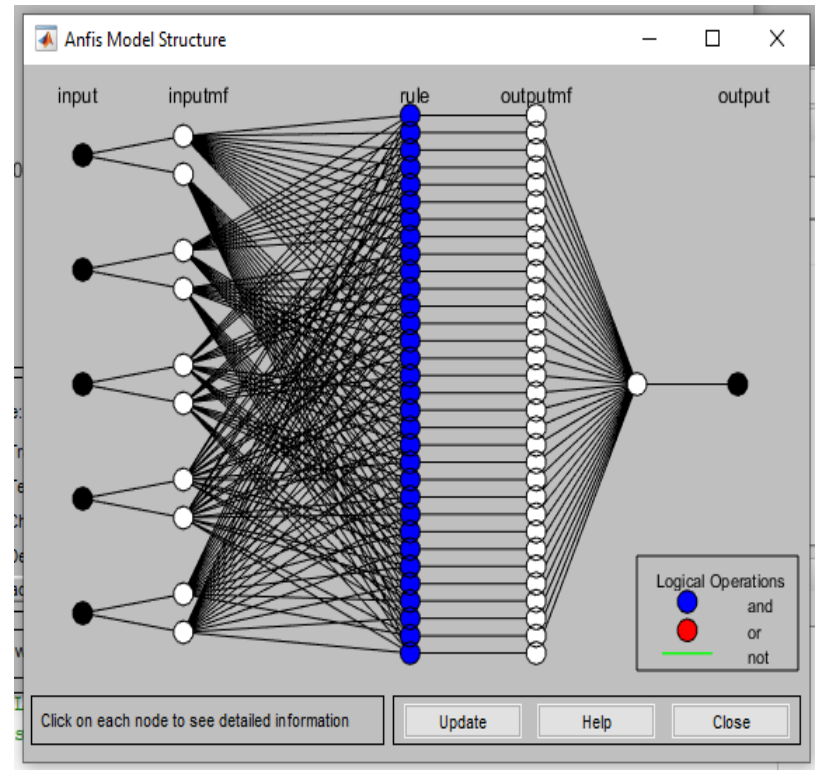

Figure 6: ANFIS model structure (by direct workspace input)

\section{Detect Submenu}

The five features of the plant is supplied at the various prompts by the user, clicking the detect button automatically processes the data supplied and confirms the presence or absence of leghemoglobin in the plant. This is clearly shown in Figure7. The detect button is used to command the system to check the existence of leghemoglobin in the plants which dataset has been supplied under the five variables Colour, Stipules, Pod, Nodules and C-Section. After training the ANFIS to learn plant morphological features, the user must supply the data for the specific plants being tested in the spaces provided. Then the system can determine and confirm the existence of leghemoglobin in the plant by the displaying "Leghemoglobin Present" or "Leghemoglobin Not Present".
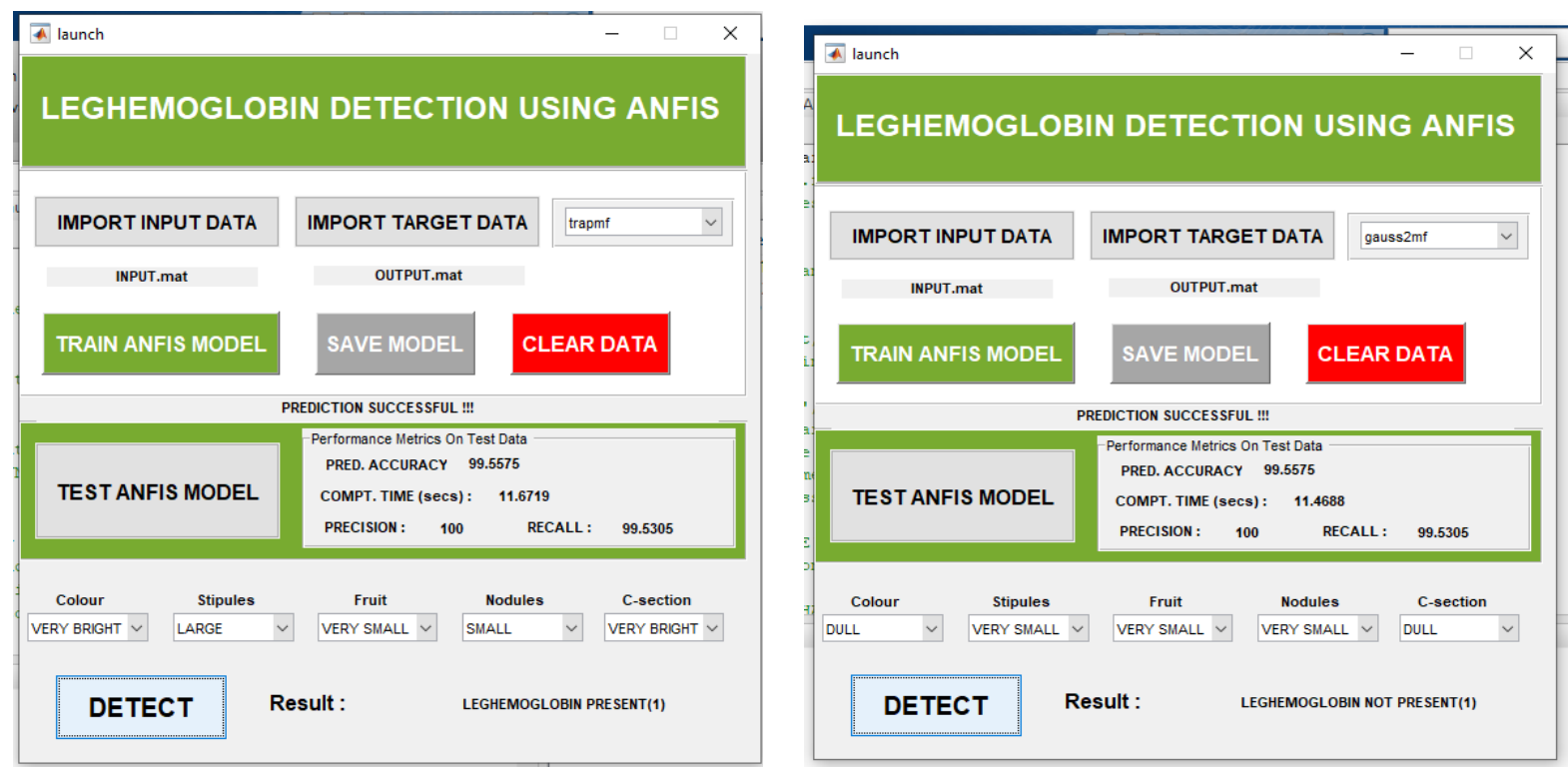

Figure 7: Result windows showing presence or not of leghemoglobin 
Table 2 is the test data. This is the sample from the test data. They are supplied directly to the variables labeled Colour, Stipules, Pod, Nodules and C-Section. The system uses this to detect and confirms the existence or presence of leghemoglobin the plants. It can actually show the if leghemologin is either present or not present in the plant.

Table 2: Test Data

\begin{tabular}{clllll}
\hline S/N & Colour & Stipule & Pods & Nodules & CCSR \\
\hline 1 & Very Bright & Large & Very Small & Large & Bright \\
2 & Very Bright & Large & Very Small & Large & Bright \\
3 & Very Bright & Large & Very Small & Large & Very Bright \\
4 & Very Bright & Very Small & Small & Very Small & Dull \\
5 & Very Bright & Small & Large & Very Small & Dull \\
6 & Very Bright & Small & Large & Very Small & Dull \\
7 & Very Bright & Very Small & Large & Small & Dull \\
8 & Very Bright & Small & Small & Very Small & Dull \\
9 & Very Bright & Large & Very Small & Large & Very Bright \\
10 & Very Bright & Large & Very Small & Large & Very Bright \\
11 & Bright & Large & Very Small & Large & Very Bright \\
12 & Bright & Large & Very Small & Large & Very Bright \\
13 & Very Bright & Large & Very Small & Large & Very Bright \\
14 & Bright & Very Small & Small & Very Small & Dull \\
15 & Bright & Very Small & Small & Very Small & Dull \\
16 & Very Bright & Very Small & Small & Very Small & Dull \\
17 & Dull & Large & Very Small & Large & Very Bright \\
18 & Dull & Small & Very Small & Small & Bright \\
19 & Dull & Very Small & Very Small & Small & Bright \\
20 & Dull & Large & Very Small & Small & Bright \\
21 & Very Bright & Large & Very Small & Large & Very Bright \\
22 & Dull & Very Small & Very Small & Large & Bright \\
23 & Very Bright & Large & Very Small & Large & Very Bright \\
24 & Very Bright & Large & Very Small & Large & Very Bright \\
25 & Bright & Small & Very Small & Large & Very Bright \\
24 & Very Bright & Large & Very Small & Large & Very Bright \\
25 & Bright & Small & Very Small & Large & Very Bright \\
\hline
\end{tabular}

\section{${ }^{*}$ Color of Cross Section of Root}

Seven Hundred and Fifty Three (753) instances of plants as a total number of dataset was used (Table 3). The dataset was partitioned into training and test set using 70:30 splitting ratio as the training set is comprised of 527 plant instances while the test set is comprised of 226 plant instances. The training set was used to train the developed model, while the test set was used to validate the performance of the trained model. 
Table 3: Plant Distribution

\begin{tabular}{lcccc}
\hline \multirow{2}{*}{ Class Labels } & \multicolumn{4}{c}{ Plant Dataset } \\
\cline { 2 - 5 } & Training & Training $\%$ & Testing & Testing \% \\
\hline Leghemoglobin (1) & 430 & 81.59 & 213 & 94.24 \\
Non- Leghemoglobin (0) & 97 & 18.41 & 13 & 5.76 \\
Total & $\mathbf{5 2 7}$ & $\mathbf{1 0 0}$ & $\mathbf{2 2 6}$ & $\mathbf{1 0 0}$ \\
\hline
\end{tabular}

Using confusion matrix for testing the accuracy and recall of the system, it yielded $99.56 \%$ and 99.53 respectively for triangular, trapezoidal and Gaussian combination membership functions; and 100\% for Gaussian function. The computational time stabilized between 11.91 seconds and 12.20 seconds.

\section{CONCLUSION}

We developed a neuro-fuzzy expert system for detection of leghemoglobin in legumes. The competence level of the system is up to the level of an expert in the subject domain of leghemoglobin. The developed system is efficient, reliable, cost-effective and has a good response result of an acceptable percentage (99.5\%). It can be utilized by experts (training experts too) and non-experts in getting vital information about leghemoglobin and aiding as a quick reference in a laboratory setting. This system is recommended for food experts, botanists and dieticians to help deal with malnutrition and health hazards emanating from eating meat, especially at specific ages. The system should be localized into indigenous languages for coverage of a bigger audience.

\section{REFERENCES}

1. Olanloye, D.O. (2017). Development of an artificial intelligence geoinformatics system for solid minerals prospecting. Unpublished doctoral dissertation, Department of Computer Science, Faculty of Physical Sciences, Nnamdi Azikiwe University, Awka.

2. Vandal Smith (2010). Application of neural network in whether prediction. The Pacesetter, 10(3), 25-35.

3. Allender, C. (2011). The second report on the state of the world's plant genetic resources for Food and Agriculture. Rome: Food and Agriculture Organisation of the United Nations (2010), 370.

4. Negnevitsky, M. (2005). Artificial intelligence: A guide to intelligent systems. Second Edition. England: Pearson Education Limited.

5. McCarthy, J. (2007). What is artificial intelligence? Stanford University, Computer Science Department. Revised Nov, 2007.

6. Tung, B. and Jintae, L. (1999). An agent-based framework for building decision support systems. Decision Support Systems, 25(3), 225-237. doi:10.1016/S0167-9236(99) 00008-1.

7. International Labour Office (updated 2017). United Nations: Digital Library; Tripartite World Conference on Employment, Incomme Distribution and Social Progress, and the International Division of Labour (1976, Geneva) 875140. www.digital library.un.org/records.

8. Krans, B. (2016). Balanced diet. Accessed October 10, 2019 from https://www.healthline.com/health/balanced-diet/overview/

9. Collins, C. (2017). What is a balanced diet anyway? The Conversation: Eating Science. Accessed October 10, 2019 from https://theconversation.com/what-is-a-balanced-diet-anyway/

10. Kubala (2018) Kubala, J. (2018). Essential amino acids: Definition, benefits and food sources. Accessed October 10, 2019 from https:/www.healthline.com/nutrition/essential-amino-acids.

11. Ware, M. (2017). How to get enough protein. Medical News Today, Accessed October 10, 2019 from https://www.medicalnewstoday.com/articles/310118.php 
12. Towler, B.F. (2014). How is Energy Measured? The Future of Energy, Elsevier Inc.,: Academy Press. 17-26. https://doi.org/10.1016/C2013-0-19049-6

13. Yingling, G.L. (2017).Gras notification for soy leghemoglobin protein preparation derived from pichia pastoris. Submitted by Impossible Foods Inc. Redwood City, CA 94063 to GRAS Notice (GRN) No.737. Retrieved from https://www.fda.gov/food/ingredientspackaging-labelling/gra/noticeinventory/ default.htm

14. Fraser, R.Z., Shitut, M., Agrawal, P., Mendes, O. and Klapholz, S. (2018). Safety evaluation of soy leghemoglobin protein preparation derived from pichia pastoris, intended for use as a flavor catalyst in plant-based meat. International Journal of Toxicology, 37(3), 241-262.

15. Surhatono, D, Aditya, W. Lestari, M. and Yasin, M. (2013). Expert system in detecting coffee plant diseases. International Journal of Electrical Energy, 1(3), 156-162.

16. Zhang, W. (2015). Adaptive decoupling control and energy efficient system for meat drying processing based on neuro fuzzy approaches. A Thesis Presented to the Department of Electrical Engineering, Faculty of Engineering, University of Guelph, Ontario, Canada.

17. Shamkuwar, D.O, Thakre, G, More, A.R, Gajakosh, K.S and Yewale, M.O. (2018). An expert system for plant disease diagnosis by using neural network. International Research Journal of Engineering and Technology (IRJET), 5(4). 369-372..

18. Sitanggang, D. et al. (2018). Application of forward-chaining method to diagnosis of onion plant diseases. Journal of Physics: Conference Series, Vol., 1007, International Conference on Mechanical, Electronics, Computer and Industrial Technology, 6-8 December, 2017, Prima, Indonesia.

19. Wijaya, R., Hariono, B, Saputra, T. and Rukmi, D. (2019). Development of plant monitoring system based on multi camera image processing techniques on hydroponic systems. Second International Conference on Food and Agriculture 2019 IOP Conf. Series: Earth and Environmental Science 411 (2020) 012002. IOP Publishing doi: 10.1088/1755-1315/411/1/012002. 